\title{
The extracellular matrix in myocardial injury, repair, and remodeling
}

\author{
Nikolaos G. Frangogiannis \\ Wilf Family Cardiovascular Research Institute, Department of Medicine (Cardiology), Albert Einstein College of Medicine, New York, New York, USA.
}

\begin{abstract}
The cardiac extracellular matrix (ECM) not only provides mechanical support, but also transduces essential molecular signals in health and disease. Following myocardial infarction, dynamic ECM changes drive inflammation and repair. Early generation of bioactive matrix fragments activates proinflammatory signaling. The formation of a highly plastic provisional matrix facilitates leukocyte infiltration and activates infarct myofibroblasts. Deposition of matricellular proteins modulates growth factor signaling and contributes to the spatial and temporal regulation of the reparative response. Mechanical stress due to pressure and volume overload and metabolic dysfunction also induce profound changes in ECM composition that contribute to the pathogenesis of heart failure. This manuscript reviews the role of the ECM in cardiac repair and remodeling and discusses matrix-based therapies that may attenuate remodeling while promoting repair and regeneration.
\end{abstract}

\section{Introduction}

The mammalian myocardium comprises cardiomyocytes and large populations of interstitial noncardiomyocytes (1) enmeshed within an intricate network of extracellular matrix (ECM) proteins. In health, the cardiac ECM does not simply serve as a mechanical scaffold, but may also transduce signals that are important for cell survival and function. Most cardiac pathologic conditions are associated with expansion of the cardiac interstitial matrix and with marked alterations in its composition $(2,3)$; these changes perturb cardiac systolic and diastolic function. In myocardial infarction, sudden death of up to a billion cardiomyocytes overwhelms the extremely limited regenerative capacity of the adult mammalian heart. As a result, the infarcted ventricle heals through activation of a superbly orchestrated cellular response that clears the wound of dead cells and matrix debris, ultimately leading to formation of a collagen-based scar (4). In conditions associated with pressure or volume overload, dynamic alterations in the ECM network may affect cardiomyocyte survival and may regulate the response of interstitial cells to mechanical stress. Metabolic diseases are also associated with profound alterations in the composition of the cardiac ECM that contribute to the pathogenesis of diastolic dysfunction and may suppress the myocardial reparative reserve. Despite increased recognition of its role in mediating cell biological responses, the contribution of the ECM in cardiac pathophysiology remains underappreciated. This Review discusses the dynamic alterations of the ECM following cardiac injury and their contribution to cardiac remodeling and function.

\section{The ECM network in the normal mammalian heart} The myocardial matrix network comprises primarily fibrillary collagen that is organized on three interconnected levels: the endomysium surrounds individual cardiomyocytes, the perimysium

Conflict of interest: The author has declared that no conflict of interest exists. Reference information: / Clin Invest. 2017;127(5):1600-1612.

https://doi.org/10.1172/JCl87491. defines major bundles, and the epimysium encases the entire cardiac muscle $(5,6)$. In all mammalian species studied to date, type I collagen is the major structural component of the cardiac interstitium, accounting for approximately $85 \%$ to $90 \%$ of the collagenous matrix (7), and is predominantly localized in the epimysium and perimysium. In contrast, type III collagen represents $5 \%$ to $11 \%$ of total myocardial collagen and is more prominent in the endomysium (7-9). In addition to collagens, the cardiac ECM also contains fibronectin, glycosaminoglycans, and proteoglycans, and it serves as a reservoir for growth factors and proteases, which are stored in the normal matrix and can be activated following injury. Although the role of the matrix network in providing structural support, preserving ventricular geometry, and facilitating force transmission is intuitive, the collagen-based cardiac matrix also transduces key signals necessary for survival and function of both cardiomyocytes and noncardiomyocytes. The molecular pathways responsible for the interactions between matrix proteins and the cellular elements in normal hearts remain poorly understood.

\section{Alterations of the ECM network following myocardial infarction}

Repair of the infarcted myocardium can be divided into three distinct but overlapping phases: the inflammatory phase, the proliferative phase, and the maturation phase (10). In all three phases of infarct healing, the dynamic changes in the composition of the ECM play a critical role in regulation of the cellular responses that mediate cardiac repair (11). During the inflammatory phase, early degradation of matrix proteins generates bioactive fragments (termed matrikines) that may contribute to activation of inflammatory and reparative cascades (Figure 1). Moreover, formation of a provisional matrix network derived from extravasated plasma proteins serves as a highly plastic conduit for infiltrating inflammatory cells. Removal of dead cells and matrix debris by professional phagocytes induces release of antiinflammatory mediators, marking the transition to the proliferative phase of cardiac repair. At this stage, the ECM is enriched through induction and deposition of matricellular 
A

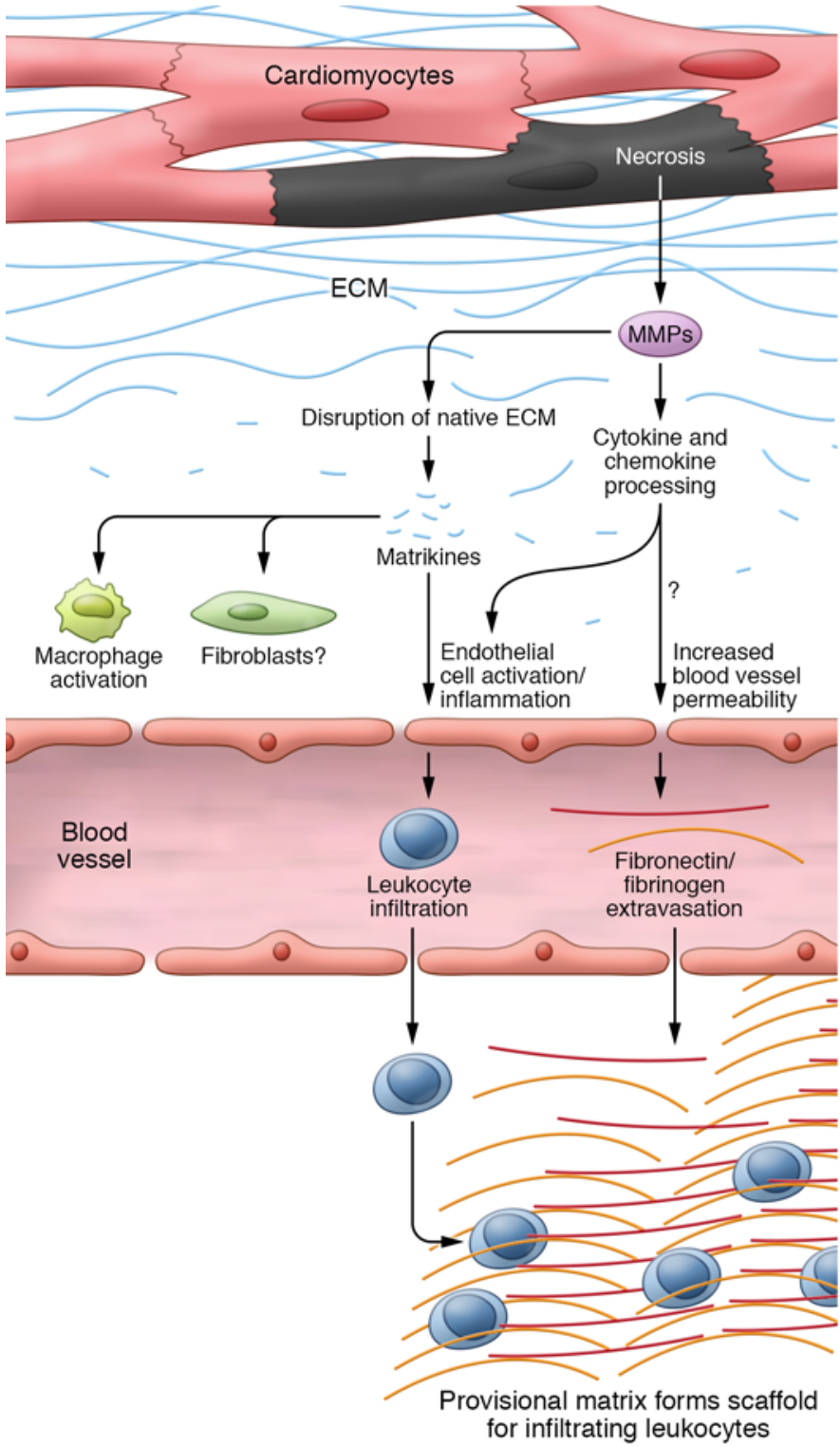

B

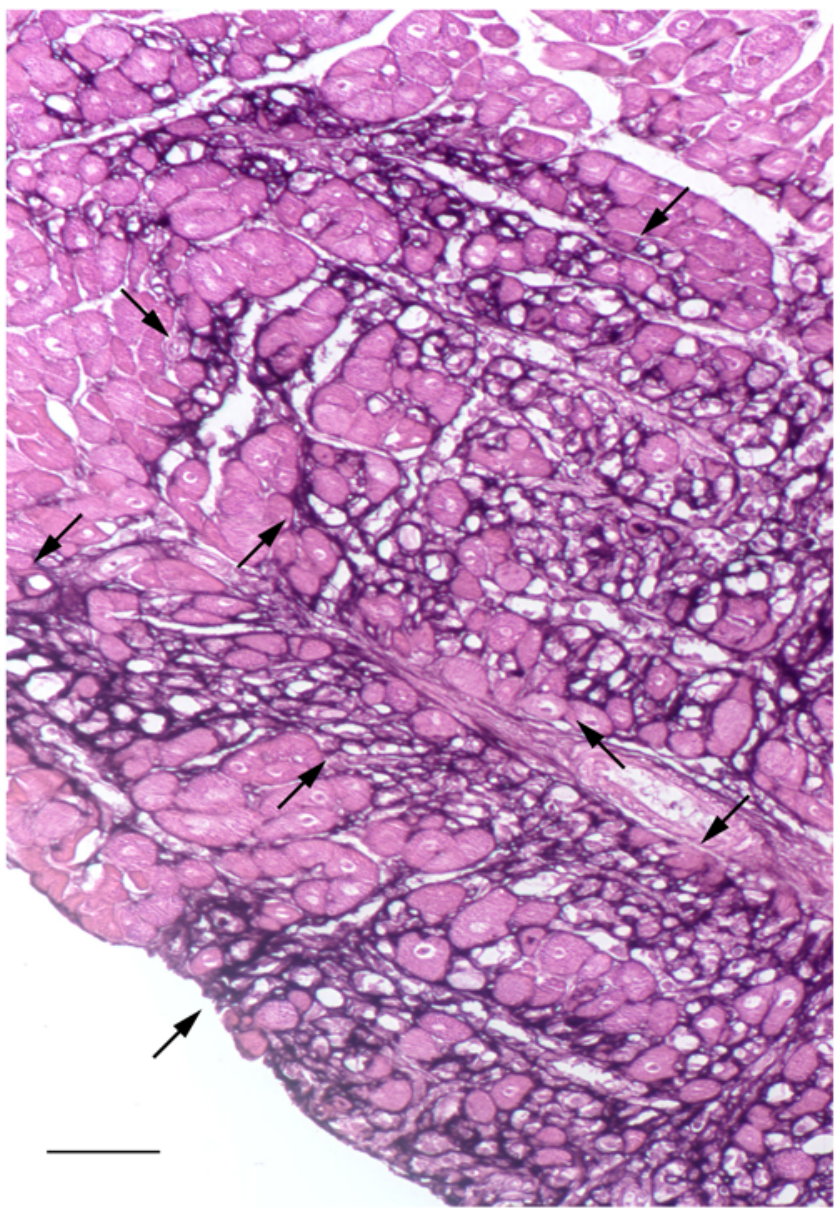

Figure 1. The ECM during the inflammatory phase of cardiac repair. (A) Cardiomyocyte necrosis is associated with induction and activation of proteases in the infarcted region. Activated proteases cause fragmentation of the native ECM, resulting in release of matrikines, bioactive peptides that activate an inflammatory macrophage phenotype and may also modulate responses of fibroblasts and vascular endothelial cells. The effects of MMPs in the ischemic and infarcted myocardium are not limited to the ECM. MMPs may modulate inflammatory and reparative responses by processing cytokines and chemokines. They may also inhibit chemokine actions by degrading glycosaminoglycan-binding sites and mediate dysfunction by targeting intracellular proteins. Increased vessel permeability in the infarcted region results in extravasation of plasma proteins, such as fibrinogen and fibronectin. Accumulation of these proteins in the infarcted region forms a provisional matrix that serves as a scaffold for infiltrating leukocytes. Fibrin and fibronectin modulate the phenotype of immune and reparative cells through integrin-mediated actions. (B) Fibrinogen/fibrin staining using a peroxidase-based technique (black) illustrates the formation of the provisional fibrin-based matrix network (indicated by arrows) in the infarcted canine myocardium (one hour ischemia followed by seven days reperfusion). Counterstained with eosin. Scale bar: $50 \mu \mathrm{m}$. Reproduced with permission from the FASEB Journal (155).

proteins, defined as extracellular macromolecules that do not serve a primary structural role, but modulate cellular phenotype, activate proteases and growth factors, and transduce signaling cascades (12, 13). Activated myofibroblasts are the dominant cells during the proliferative phase of cardiac repair and deposit large amounts of structural ECM proteins. Finally, during the maturation phase, crosslinking of the ECM, fibroblast quiescence, and vascular maturation lead to formation of a stable collagen-based scar.

\section{ECM during the inflammatory phase of cardiac repair}

Activation of matrix metalloproteinases. Myocardial ischemia causes rapid activation of latent matrix metalloproteinases (MMPs) and subsequent generation of matrix fragments (14, 15). MMP activation is detected in the cardiac interstitium as early as ten minutes after coronary occlusion (16), before any evidence of irreversible cardiomyocyte injury, and may be driven by ischemia- 
mediated ROS generation (17). Cardiomyocyte necrosis accentuates the matrix-degrading response. Large amounts of MMPs are synthesized de novo by ischemic cardiomyocytes, fibroblasts, endothelial cells, and inflammatory leukocytes that infiltrate the infarct (18). Both collagenases (e.g., MMP1) and gelatinases (MMP2 and MMP9) are upregulated in the infarcted myocardium (19).

It should be emphasized that the actions of MMPs are not limited to effects on the ECM. MMPs regulate inflammatory responses through proteolytic processing of cytokines, chemokines, and growth factors (20-24) or by degrading glycosaminoglycan binding sites, thus interfering with a molecular step that is critical for chemokine immobilization on the endothelial cell surface and subsequent interaction with leukocytes (25). MMPs also have intracellular targets, degrading cardiomyocyte proteins, such as myosin, $\alpha$-actinin, and titin (26-28). The relative significance of the matrix-independent actions of MMPs in the pathogenesis of ischemic dysfunction and postinfarction remodeling remains unknown.

Generation of matrikines. In injured and remodeling tissues, protease-mediated fragmentation of matrix proteins results in generation of matrikines (29-32). Elastin fragments and collagen-derived peptides are the best-studied matrikines and have been implicated in activation of immune cells and fibroblasts $(29,33)$. The collagen-derived tripeptide proline-glycine-proline (PGP) and its acetylated form have been demonstrated as acting as neutrophil chemoattractants in models of pulmonary inflammation, signaling through activation of the chemokine receptor CXCR2 (34). PGP generation requires activation of a multistep cascade that involves MMP8, MMP9, and prolyl endopeptidase (35). Proteolytic processing of laminins by MMP2 and MMP14 has also been demonstrated as yielding fragments with potent neutrophil chemoattractant properties (36).

Although the rapid activation of MMPs in the infarct is associated with matrix fragmentation, the role of these fragments as bioactive proinflammatory matrikines has not been documented. In experimental models, release of type I collagen fragments in the serum has been documented within 30 minutes after coronary occlusion (37). Fragmentation of components of the basement membrane, such as collagen IV, and of noncollagenous matrix constituents has also been demonstrated in the infarcted myocardium (38-41). Low-molecular weight hyaluronan fragments exert potent proinflammatory actions in the infarcted region; impaired clearance of these fragments has been shown to prolong and accentuate proinflammatory signaling in leukocytes and vascular cells $(42,43)$. Matrix fragments may also modulate fibroblast and vascular cell phenotype (44). Endostatin, a 20-kDa fragment of collagen XVIII, exerts potent angiostatic actions (45) and stimulates fibroblast proliferation (46). MMP9-mediated cleavage of collagen IV also generates fragments with angiostatic properties, such as tumstatin (47). The role of endogenous matrix fragments in regulation of fibrogenic and angiogenic responses following myocardial infarction remains poorly understood.

The plasma-derived provisional matrix regulates the inflammatory response. Degradation of the original cardiac matrix network in the infarcted myocardium is accompanied by formation of a provisional matrix (39). Rapid induction of VEGF in the infarcted heart increases vascular permeability (48), leading to extravasation of plasma fibrinogen and fibronectin and generating a complex and dynamic fibrin-based matrix network $(39,49)$. The role of the provisional matrix in regulating cardiac repair remains poorly understood; current concepts are predominantly based on extrapolation of findings from studies that investigate reparative responses in other systems. In addition to its hemostatic role, the provisional matrix may serve as a scaffold for migrating inflammatory cells and support proliferating endothelial cells and fibroblasts (50). Components of the provisional matrix interact with migrating cells through cell surface integrins (51) and may also transduce signaling cascades that modulate immune cell phenotype and gene expression (52). In vitro, fibrinogen stimulates macrophagederived chemokine secretion through TLR4 activation (53).

In a mouse model of reperfused myocardial infarction, fibrin-mediated interactions contributed to early injury by accentuating the inflammatory response (54). Treatment with a naturally occurring peptide that competes with the fibrin fragment $\mathrm{N}$-terminal disulfide knot-II (an analog of the fibrin E1 fragment) for binding to vascular endothelial cadherin reduced infarct size, attenuating leukocyte infiltration in the ischemic myocardium in both rodent and large animal models $(54,55)$. Unfortunately, the effects of the peptide in a small clinical trial were much less impressive. Peptide administration in patients with ST-elevation myocardial infarction (STEMI) did not affect the size of the infarct assessed through magnetic resonance imaging and did not reduce serum troponin I levels (56).

The provisional matrix may also play an important role in the transition to the proliferative phase of cardiac repair by serving as a reservoir for cytokines and growth factors. The heparin-binding domain of fibrin binds to a wide range of growth factors, including members of the PDGF, FGF, VEGF, and TGF families (57), that may activate reparative fibroblasts and vascular cells.

\section{ECM during the proliferative phase of infarct healing}

Dynamic changes in the composition of the ECM may contribute to the reparative cellular responses during the proliferative phase of cardiac repair (Figure 2). Clearance of matrix fragments by phagocytes may activate antiinflammatory signals, suppressing recruitment of proinflammatory leukocytes. Lysis of the plasma-derived provisional matrix is followed by organization of a cell-derived matrix network, comprising cellular fibronectin, hyaluronan, proteoglycans, and a wide range of matricellular macromolecules (39) that transduce growth factor signals to reparative cells (58). The dynamic alterations of the ECM during the proliferative phase provide essential signals for conversion of fibroblasts into myofibroblasts and may activate angiogenic pathways necessary for neovessel formation, thus supplying the metabolically active wound with oxygen and nutrients (11).

Fibrin network clearance and cell-derived provisional matrix formation. In healing wounds, the plasma-derived ECM is cleared through extracellular proteolysis by fibrinolytic enzymes (59) and through endocytosis by CCR $2^{+}$macrophages (60). In the healing infarct, clearance of the fibrin-based provisional matrix by the plasminogen/plasmin system is an important part of the reparative response. Mice lacking plasminogen exhibited markedly attenuated recruitment of inflammatory leukocytes in the infarct and impaired granulation tissue formation (61). Lysis of the fibrin-based 
A

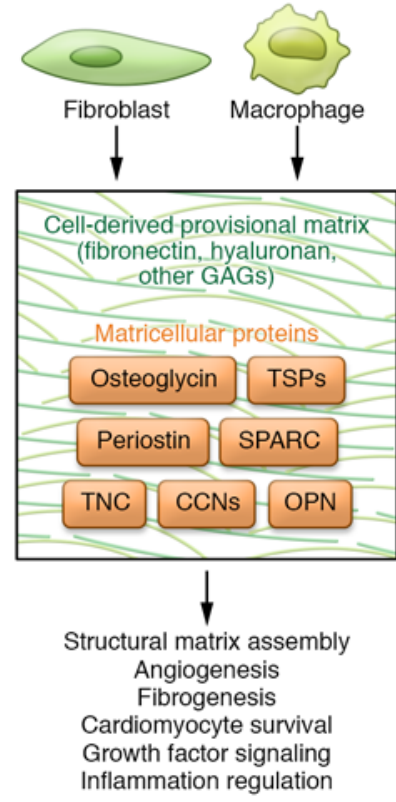

Figure 2. The role of the cell-derived provisional matrix in cardiac repair. (A) During the proliferative phase of cardiac repair, fibroblasts and macrophages contribute to the formation of a cell-derived provisional matrix, enriched with a wide range of matricellular macromolecules that do not serve a primary structural role, but modulate cellular phenotype and function. Specialized matrix proteins (such as ED-A domain fibronectin) and matricellular proteins, such as TSPs, tenascin-C (TNC), osteopontin (OPN), SPARC, periostin, osteoglycin, and members of the CCN family, bind to the matrix and modulate growth factor and protease activity. Specific matricellular proteins have been reported as regulating inflammation, participating in fibrogenic and angiogenic responses, modulating cardiomyocyte survival, and contributing to assembly of the structural matrix. (B) Matricellular proteins may be critical in spatial and temporal regulation of growth factor signaling. Immunohistochemical staining using a peroxidase-based technique (black) shows the strikingly selective localization of the prototypical matricellular protein TSP1 (arrows), a critical activator of TCF- $\beta$, in the border zone of a healing canine myocardial infarction (one hour ischemia followed by seven days reperfusion). Spatially and temporally restricted induction of matricellular proteins regulates growth factor signaling, preventing expansion of profibrotic responses beyond the infarcted area, despite possible diffusion of the soluble mediators in viable segments. Counterstained with eosin. Reproduced with permission from Circulation (75). Scale bar: $50 \mu \mathrm{m}$. GAGs, glycosaminoglycosans.

matrix is followed by secretion of cellular fibronectin by fibroblasts and macrophages $(62,63)$ and by deposition of hyaluronan and versican, forming a network of cell-derived provisional matrix that is later enriched with a wide range of matricellular macromolecules (12). During the proliferative phase of healing, the highly dynamic matrix becomes a regulatory center that transduces essential signals to activate reparative fibroblasts and vascular cells.

Components of the provisional matrix regulate fibroblast activation. Repair of the infarcted heart is dependent on recruiting and activating resident fibroblast populations (64) to acquire a myofibroblast phenotype that expresses contractile proteins such as $\alpha$-smooth muscle actin ( $\alpha$-SMA) and secretes large amounts of collagens. Myofibroblast transdifferentiation requires cooperation between soluble growth factors, such as TGF- $\beta 1$, and components of the provisional matrix. In vitro, the ED-A domain splice variant of fibronectin is critical for TGF- $\beta 1$-mediated $\alpha$-SMA upregulation (65). In vivo, ED-A fibronectin loss attenuates myofibroblast transdifferentiation in healing myocardial infarction (66). The specific interactions between the ED-A segment and the TGF- $\beta$-signaling cascade remain unknown. Hyaluronan and versican have also been implicated in myofibroblast conversion. In vitro, pericellular hyaluronan was required to maintain a myofibroblast phenotype in TGF- $\beta$-stimulated cells (67). In vivo, loss of $\mathrm{CD} 44$, the main receptor for haluronan, impaired collagen synthesis in infarct fibroblasts (40). Versican loss in dermal fibroblasts attenuated myofibroblast conversion (68). Although versican is upregulated in healing myocardial infarcts (69), its in vivo role in transdifferentiation of injury-site cardiac myofibroblasts has not been directly documented.

Induction of matricellular proteins. During the proliferative phase of infarct healing, the cardiac ECM is enriched through the deposition of a wide range of structurally diverse matricellular proteins that do not serve a direct structural role, but act contextually by regulating cytokine and growth factor responses and modulating cell phenotype and function $(70,71)$. The family includes the thrombospondins TSP$1,-2$, and -4 , tenascin- $C$ and $-X$, secreted protein, acidic and cysteine-rich (SPARC), osteopontin, periostin, and members of the CCN family (72). Several other proteins (including members of the galectin and syndecan family, fibulins, osteoglycin, and other small leucine-rich proteoglycans) have been found to exert matricellular actions as part of their broader spectrum of functional properties. Most members of the matricellular family show low expression in the normal myocardium, but are markedly upregulated following myocardial injury. In healing infarctions, angiotensin and growth factors stimulate de novo synthesis and secretion of matricellular proteins in fibroblasts or immune or vascular cells $(39,73,74)$. Once secreted into the interstitium, matricellular macromolecules bind to the structural matrix and transduce signaling cascades through ligation of cell surface receptors or contribute to activation of cytokines, growth factors, and proteases in the pericellular space. An overview of the pattern of regulation, function, targets, and mechanisms of action of the matricellular proteins discussed below is given in Table 1 .

Several prototypical members of the matricellular family are markedly upregulated following myocardial infarction and protect the myocardium from adverse remodeling (75-78). Localized induction of TSP- 1 in the infarct border zone may form a barrier that prevents expansion of inflammation in viable myocardial areas through local activation of antiinflammatory signals (75). Osteopontin may protect from left ventricular dilation by promoting matrix deposition in the infarcted region (79). SPARC has been shown to protect from cardiac rupture and postinfarction heart failure by contributing to collagen maturation through activation of growth factor signaling (80). Periostin serves as a crucial regulator of fibroblast 
recruitment and activity (81) and prevents cardiac rupture (81, 82), promoting formation of an organized collagen-based scar.

Although each matricellular protein has a unique functional profile, several unifying themes have emerged regarding their actions in the infarcted heart. First, the strikingly selective localization of prototypical members of the family in the infarct border zone and their regulatory effects on the activity of soluble mediators highlight their role in spatial regulation of cellular responses. Secreted growth factors and cytokines can diffuse beyond the infarct zone; the requirement for matricellular proteins in activating growth factor-mediated responses may serve to localize inflammatory and fibrotic responses within areas of injury. Second, transient expression of matricellular proteins during the proliferative phase of healing ensures temporal regulation of growth factor responses. Clearance of matricellular proteins from the infarcted area may serve as an important STOP signal, preventing uncontrolled fibrosis following injury. In vitro studies have demonstrated that alternatively activated macrophages internalize SPARC through the scavenger receptor stabilin 1 (83). However, the potential role of immune cell subsets in endocytosis and degradation of matricellular proteins in vivo has not been tested. Third, repair of the infarcted myocardium is dependent on a highly dynamic microenvironment that promotes cellular plasticity. In response to micro- environmental cues, interstitial cells exhibit phenotypic changes (84-86), leading to transitions from inflammatory to reparative phenotypes (87). Through their transient induction and incorporation into the matrix, matricellular proteins may play a critical role in regulating cell differentiation, contributing to the cellular plasticity observed in healing tissues through direct actions and via modulation of growth factor-mediated pathways.

\section{ECM in the maturation phase of infarct healing}

Scar maturation is associated with ECM crosslinking in the infarct zone and with a marked reduction in myofibroblast density (88). Descriptive studies have suggested that apoptosis may be involved in elimination of granulation tissue cells from the infarct $(89,90)$; however, the mechanisms responsible for cell-specific activation of a proapoptotic program in the late phase of infarct healing have not been investigated. Acquisition of a quiescent phenotype may precede apoptosis of infarct myofibroblasts. Formation of a mature crosslinked matrix and clearance of matricellular proteins may play an important role in regulating fibroblast deactivation in the healing infarct (91-93). It is tempting to hypothesize that endogenous mechanisms that restrain matricellular actions protect the infarcted heart from progressive fibrosis, depriving fibroblasts of the prolonged actions of growth factor-mediated signals. Vascular cells may also

\section{Table 1. Matricellular proteins in myocardial infarction}

\begin{tabular}{ll}
$\begin{array}{l}\text { Matricellular } \\
\text { protein }\end{array}$ & \multicolumn{1}{c}{ Pattern of regulation } \\
TSP-1 & $\begin{array}{l}\text { Transient upregulation and } \\
\text { deposition in the infarct border } \\
\text { zone during the proliferative phase } \\
\text { of healing }\end{array}$ \\
\hline Tenascin-C & $\begin{array}{l}\text { Transient upregulation in infarcted } \\
\text { area, border zone, and remodeling } \\
\text { myocardium }\end{array}$ \\
SPARC & $\begin{array}{l}\text { Abundant, but transient } \\
\text { upregulation in infarcted } \\
\text { myocardium, predominantly } \\
\text { localized in macrophages and } \\
\text { myofibroblasts }\end{array}$ \\
& $\begin{array}{l}\text { Markedly and transiently } \\
\text { upregulated following infarction, } \\
\text { primarily localized in macrophages }\end{array}$ \\
\hline OPN &
\end{tabular}

$\begin{array}{ll}\text { Periostin } & \begin{array}{l}\text { Marked, but transient upregulation } \\ \text { in activated myofibroblasts in } \\ \text { the infarct, border zone, and } \\ \text { remodeling area }\end{array} \\ \text { CCN2 } & \begin{array}{l}\text { Marked, but transient upregulation } \\ \text { in infarcted hearts through activation } \\ \text { of TCF- } \beta \text { and angiotensin II }\end{array}\end{array}$

Osteoglycin Marked upregulation in infarcted myocardium, associated with collagen deposition

\section{Function}

Protects the infarcted heart from adverse remodeling, limiting expansion of inflammation and extension of fibrosis

May contribute to myocardial regeneration in fish and amphibians Promotes fibrosis and adverse remodeling in mammals

Protects from cardiac rupture May promote systolic dysfunction during the early postischemic phase

Protects from adverse remodeling

Protects from cardiac rupture, while promoting late fibrosis in remodeling segments

Cardiomyocyte-specific CCN2

overexpression studies suggested that CCN2 reduces infarct size following ischemia/reperfusion and attenuates adverse remodeling in nonreperfused infarction

Protects from cardiac rupture and prevents adverse remodeling

\section{Possible cellular targets}

Fibroblasts, macrophages, vascular endothelial cells, T cells, cardiomyocytes

Fibroblasts, cardiomyocytes, macrophages, vascular cells

Fibroblasts, macrophages, vascular cells

Fibroblasts, macrophages, T cells, vascular cells, cardiomyocytes

Fibroblasts

Possible mechanisms of action

References

Activates TGF- $\beta$

12

Inhibits MMPs

Exerts angiostatic actions

Exerts antiinflammatory actions

Modulates nitric oxide signaling

Exerts proinflammatory actions

$145,156,157$

Triggers fibrogenic actions though

accentuation of growth factor signaling

Promotes angiogenic effects

Regulates matrix assembly and

80,158

metabolism

Accentuates growth factor signaling,

promoting fibroblast activation and

angiogenesis

Regulates matrix assembly

79

Activates growth factor signaling,

promoting fibroblast activation and angiogenesis

Regulates matrix assembly

Activates a fibrogenic program

Cardiomyocytes, fibroblasts, macrophages

Activates prosurvival pathways in

159, 160

cardiomyocytes

Attenuates inflammation

Fibroblasts

Regulates maturation of collagen fibers

161 


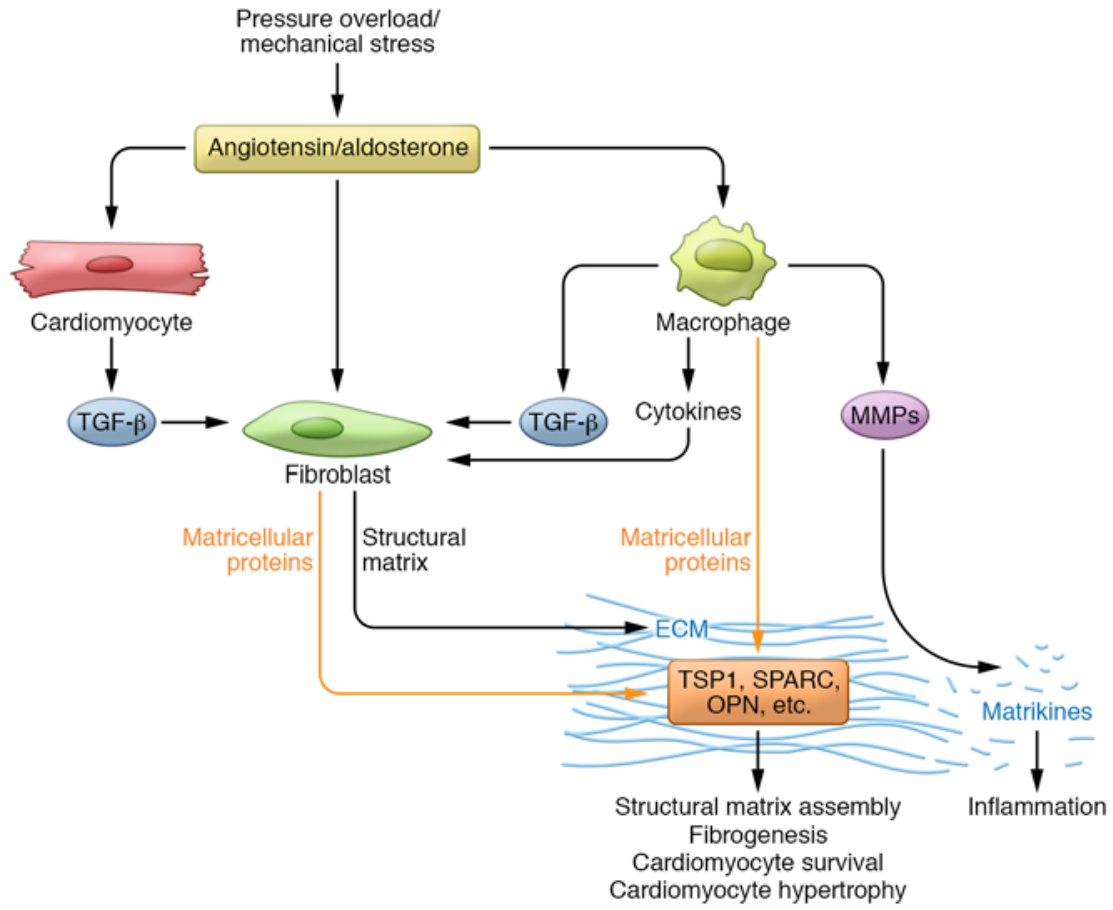

Figure 3. Matricellular proteins regulate cellular responses in the pressure-overloaded myocardium. In the pressure-overloaded heart, mechanical stress activates neurohumoral pathways and induces synthesis and release of matricellular macromolecules, including TSP1, -2 , and -4 , tenascin-C, OPN, SPARC, and periostin. Matricellular proteins have been implicated in regulation of matrix assembly, in transduction of mechanosensitive signaling, and in the pathogenesis of fibrosis and cardiac hypertrophy, and may also modulate survival of cardiomyocytes under conditions of stress. The effects of the matricellular proteins are exerted through direct activation of cell surface receptors or through modulation of growth factor- and protease-mediated responses.

respond to the mature ECM environment. During scar maturation, infarct microvessels acquire a coat of mural cells through activation of PDGFR- $\beta$ signaling $(88,94)$; uncoated vessels regress. ECM proteins have been implicated in modulation of endothelial-pericyte interactions in vitro and in vivo $(95,96)$, but whether such effects play a role in maturation of infarct microvessels remains unknown.

It should be emphasized that in the presence of a large infarction with significant hemodynamic consequences, viable noninfarcted myocardium also exhibits slowly progressive interstitial fibrosis related to the pathophysiologic effects of pressure and volume loads. Inflammation and fibrosis are suppressed in the healing infarct, leading to formation of a mature collagen-based scar, but in the viable noninfarcted zone, increased wall stress may locally activate macrophages and fibroblasts, triggering chronic progressive expansion of the cardiac interstitial matrix $(97,98)$.

\section{ECM in cardiac pressure and volume overload}

Pressure and volume overload are critically implicated in the pathogenesis of heart failure in a wide variety of cardiac conditions. Left ventricular pressure overload is the critical pathophysiologic companion of the cardiomyopathy induced by systemic hypertension and aortic stenosis. On the other hand, valvular regurgitant lesions (such as aortic and mitral insufficiency) cause cardiac remodeling and heart failure by subjecting the heart to volume overload. Moreover, both pressure and volume loads contribute to the pathophys- iology of postinfarction remodeling. Pressure and volume overload have distinct effects on the cardiac ECM that may account for their consequences on ventricular geometry and function.

ECM in the pressure-overloaded myocardium. In both experimental models and in human patients, cardiac pressure overload causes early hypertrophic remodeling and diastolic dysfunction, followed by decompensation, chamber dilation, and development of systolic heart failure. Pressure overload is associated with profound and dynamic changes in the composition of the ECM; these changes regulate geometry and function, not only by affecting the mechanical properties of the ventricle, but also by modulating cellular responses. In animal models, activation of cardiac fibroblasts is one of the earliest effects of pressure overload in the myocardium, ultimately leading to deposition of collagenous matrix and expansion of the interstitium (99-101). In human patients, hypertensive heart disease is associated with development of interstitial and periarteriolar fibrosis even in the absence of significant coronary atherosclerosis (102).

Fibrotic changes that develop in the pressure-overloaded myocardium may involve activation of cardiomyocytes, fibroblasts, and immune and vascular cells. Mechanical stress due to pressure overload activates the renin-angiotensin-aldosterone system (RAAS), triggering inflammatory signaling and leading to downstream stimulation of TGF- $\beta$ cascades. Neurohumoral mediators, cytokines, and growth factors directly stimulate a fibrogenic program, triggering myofibroblast conversion and stimulating synthesis of large amounts of structural matrix proteins (103-106). Stress-induced fibroblast activation in the pressure-overloaded myocardium may also be indirect, at least in part, requiring stimulation of fibrogenic cascades in cardiomyocytes and immune cells. Mechanical stretch has been suggested as triggering purinergic signaling in cardiomyocytes, leading to release of fibrogenic growth factors (107). Moreover, T lymphocytes and macrophages have been implicated in activation of resident cardiac fibroblasts following pressure overload $(108,109)$.

Even in the absence of cardiomyocyte necrosis, mechanically activated myofibroblasts and immune cells secrete specialized matrix proteins (such as fibronectin) and enrich the interstitial matrix with a wide range of matricellular macromolecules (Figure 3 and refs. 110, 111). Fibronectin deposition in the pressure-overloaded heart may be involved in myofibroblast transdifferentiation and has been implicated as an important mediator in cardiomyocyte hypertrophy (112), possibly through activation of growth factor signaling. Deposition of matricellular proteins in the pressure-overloaded heart generates a highly dynamic matrix microenvironment and modulates fibrogenic and hypertrophic responses. Table 2 provides an overview of the regulation, functional role, and mechanisms of action of the matricellular proteins in the pressure-overloaded myocardium. 
ECM in cardiac volume overload. Volume overload is associated with a distinct profile of changes in the composition of the ECM that ultimately lead to chamber dilation and contribute to systolic dysfunction. In contrast to the marked accentuation in collagen deposition triggered by a pressure load, volume overload is associated with a reduction in interstitial collagen content due to increased MMP expression (113-115) and augmented autophagic degradation of procollagen in cardiac fibroblasts (116). Pharmacologic inhibition studies suggested that MMP activation is directly implicated in dilative remodeling of the volume-overloaded ventricle (117), but the mechanisms responsible for the distinct cell biological changes and matrix alterations in volume overload remain poorly understood. Bradykinin receptor signaling has been implicated in matrix loss associated with volume overload (118), but the links between specific mechanical stimuli and myocardial cell activation are understudied. The limited data on the matricellular protein profile in volume-overloaded hearts are not accompanied by systematic investigations of the potential role of these proteins. Although marked increases in synthesis of fibronectin and periostin have been reported in experimental volume overload $(114,119)$, deposition of these fibrogenic matricellular proteins was not associated with increased secretion of structural matrix proteins.

\section{The cardiac ECM in metabolic disease}

Diabetics exhibit a high incidence of heart failure with preserved ejection fraction, associated with expansion of the cardiac ECM network (120). Fibrotic changes in diabetic hearts are, at least in part, independent of coronary artery disease or hypertension (121), reflecting direct effects of metabolic dysregulation on the ECM. Diabetes, obesity, and metabolic dysfunction are associated with activation of cardiac fibroblasts (122) and are accompanied by deposition of matricellular macromolecules (123) and progressive accumulation of fibrillary collagens in the cardiac interstitium $(124,125)$. The molecular basis for activation of the so-called diabetic fibroblast remains unknown. The role of hyperglycemia in mediating fibrogenic activation remains poorly defined. Whether stimulation of a fibrogenic program in diabetic fibroblasts requires diabetes-associated activation of fibrogenic signaling in cardiomyocytes, vascular, or immune cells is unclear. Expansion of the cardiac interstitium in diabetes involves activation of several distinct but overlapping pathways, including neurohumoral mediators (such as the RAAS), ROS, inflammatory cytokines and growth factors (such as TGF- $\beta$ ), adipokines, and the advanced glycation endproduct (AGE)/receptor for AGE (RAGE) axis. Moreover, hyperglycemia induces matricellular protein synthesis in several cell types (126). Diabetes-associated induction of matricellular proteins, such as

\section{Table 2. Matricellular proteins in the pressure-overloaded myocardium}

\begin{tabular}{|c|c|c|}
\hline $\begin{array}{l}\text { Matricellular } \\
\text { protein }\end{array}$ & $\begin{array}{l}\text { Pattern of regulation in models } \\
\text { of pressure overload }\end{array}$ & Function \\
\hline TSP-1 & $\begin{array}{l}\text { Transient upregulation and deposition in } \\
\text { interstitial and perivascular areas in models of } \\
\text { TAC and systemic hypertension and in a combined } \\
\text { model of hyperglycemia/abdominal aortic } \\
\text { constriction }\end{array}$ & $\begin{array}{l}\text { Activates fibroblasts in the pressure-overloaded } \\
\text { heart, promoting a matrix-synthetic phenotype }\end{array}$ \\
\hline TSP-2 & $\begin{array}{l}\text { High expression in myocardium of renin- } \\
\text { overexpressing hypertensive rats that developed } \\
\text { heart failure } \\
\text { High expression in human patients with cardiac } \\
\text { hypertrophy }\end{array}$ & $\begin{array}{l}\text { Protects the angiotensin II-stimulated myocardiun } \\
\text { from rupture } \\
\text { Protects the aging heart from dilation }\end{array}$ \\
\hline TSP-4 & $\begin{array}{l}\text { Rapid upregulation in the myocardium in response } \\
\text { to angiotensin II treatment or TAC }\end{array}$ & $\begin{array}{l}\text { Protects the pressure-overloaded heart from } \\
\text { functional decompensation, systolic dysfunction, } \\
\text { and death } \\
\text { Downmodulates the fibrotic response in the } \\
\text { pressure-overloaded heart }\end{array}$ \\
\hline Tenascin- $-\complement$ & $\begin{array}{l}\text { Deposition in the cardiac interstitium following } \\
\text { pressure overload } \\
\text { Upregulation in cardiomyocytes subjected to } \\
\text { mechanical strain }\end{array}$ & $\begin{array}{l}\text { Accelerates cardiac fibrosis in response to } \\
\text { angiotensin II infusion }\end{array}$ \\
\hline SPARC & Upregulation in models of TAC & $\begin{array}{l}\text { Mediates fibrosis and promotes diastolic } \\
\text { dysfunction in models of TAC }\end{array}$ \\
\hline OPN & $\begin{array}{l}\text { Upregulation in models of TAC and angiotensin II } \\
\text { infusion } \\
\text { Increased expression in human hypertensive heart } \\
\text { disease }\end{array}$ & $\begin{array}{l}\text { Mediates fibrosis in models of TAC, angiotensin, } \\
\text { and aldosterone infusion } \\
\text { Prohypertrophic effects are less consistently } \\
\text { observed in various models }\end{array}$ \\
\hline Periostin & $\begin{array}{l}\text { Upregulated in activated fibroblasts and deposited } \\
\text { in the cardiac interstitium in models of TAC }\end{array}$ & Promotes hypertrophy and fibrosis \\
\hline
\end{tabular}

Possible mechanisms of action

References

protein

Transient upregulation and deposition in

model of hyperglycemia/abdominal aortic

High expression in myocardium of renin-

overexpressing hypertensive rats that developed

heart failure

hypertrophy

Rapid upregulation in the myocardium in response angiotensin II treatment or TAC and death

Downmodulates the fibrotic response in the pressure-overloaded heart

Accelerates cardiac fibrosis in response to

Mediates fibrosis and promotes diastolic dysfunction in models of TAC and aldosterone infusion

Prohypertrophic effects are less consistently erved in various models

in the cardiac interstitium in models of TAC
Activates TGF- $\beta$

Inhibits MMP activity

Inhibition of MMP synthesis and activity Activation of prosurvival pathways in cardiomyocytes

Suppresses expression of ECM proteins in

$167-171$

fibroblasts and endothelial cells Activates mechanosensitive Erk and Akt signaling in cardiomyocytes, increasing contractility following pressure overload Has been suggested as also acting intracellularly, augmenting ER function and protecting from injury-related ER stress

May act in part through activation of integrin- 99, 172-174 mediated cytokine secretion in macrophages

Contributes to postsynthetic procollagen

175,176 processing

Promotes fibroblast proliferation

Activates fibroblasts through an miR-21-

mediated pathway 177-183

Activates cardiac fibroblasts, promoting their

82,184 migration and transdifferentiation Regulates collagen fibrillogenesis

TAC, transverse aortic constriction 
TSP-1, may drive the fate of cardiac interstitial cells toward a fibroblast phenotype promoting fibrotic remodeling.

\section{Therapeutic ECM targeting in injured and remodeling myocardium}

Matrix-based strategies to preserve structure, geometry, and function. Because of its importance in preserving structural integrity and function of the heart (127) and its crucial involvement in regulation of cellular responses in cardiac injury, repair, and remodeling (12), the cardiac ECM provides unique opportunities for therapeutic interventions in patients with myocardial infarction and heart failure. Several therapeutic approaches with established beneficial effects in patients with myocardial infarction and heart failure, such as ACE inhibition, angiotensin type 1 receptor blockade, $\beta$-adrenergic receptor antagonism, and mechanical unloading, may exert some of their protective actions through modulation of ECM deposition and metabolism (128).

Following myocardial infarction, catastrophic mechanical complications, such as cardiac rupture (129), are associated with accentuated matrix degradation or perturbed deposition of new structural matrix (130). These can be treated through application of a patch containing ECM proteins to restore the structural integrity of the ventricle (131). In the remodeling heart, approaches to tightly regulating matrix deposition and crosslinking may protect from adverse remodeling and development of heart failure. A large body of experimental evidence suggests that excessive accumulation of crosslinked structural matrix proteins increases myocardial stiffness and promotes diastolic dysfunction; in contrast, overactive matrix-degrading pathways may promote dilative remodeling, causing systolic dysfunction. In patients with myocardial infarction, therapeutic interventions directly targeting ECM metabolism through MMP inhibition have produced mixed results. Administration of a selective oral MMP inhibitor in patients with STEMI and reduced ejection fraction showed no significant protection from adverse remodeling (132), despite significant antiremodeling effects in animal models. In contrast, early nonselective MMP inhibition with doxycycline attenuated progression to dilative remodeling in patients with STEMI and left ventricular dysfunction (133). The conflicting findings may reflect the pathophysiological heterogeneity of human myocardial infarction; successful implementation of matrix modulation strategies may require development of biomarkers or imaging approaches to identify patients with specific alterations in matrix metabolism (134). Moreover, interpretation of the effects of therapies targeting MMPs are complicated by their wide range of actions beyond matrix metabolism involving processing and modulation of bioactive cytokines and growth factors.

Matrix-based interventions to modulate cellular cardiac repair responses. Specialized matrix proteins and matricellular macromolecules critically modulate the cellular responses in the infarcted and remodeling heart and may hold the key for development of new effective strategies to optimize repair and to reduce adverse remodeling following cardiac injury. Animal model studies have suggested that several members of the matricellular family protect the infarcted heart from adverse remodeling (12). Therapeutic approaches based on matricellular proteins are particularly attractive because of the capacity of matricellular macromolecules to modulate growth factor and cytokine signaling, thus localizing therapeutic effects in the area of interest. Unfortunately, the daunting complexity of the biology of matricellular proteins hampers therapeutic implementation. Matricellular proteins have multiple functional domains and act contextually depending on microenvironmental factors, such as the local composition of the matrix and the profile of cytokine and growth factor expression. Distinct actions of matricellular protein fragments further complicate therapeutic implementation. Identification of the functional domains responsible for specific protective or detrimental matricellular actions is needed in order to design peptide-based strategies that simulate these effects $(12,135)$.

Targeting the ECM to promote cardiac regeneration. In contrast with fish and amphibians, adult mammals have very limited capacity for myocardial regeneration (136), which is overwhelmed by the massive sudden loss of cardiomyocytes following infarction. Over the last 15 years, a wide range of cell therapy approaches has been tested in attempts to regenerate the injured human myocardium, with little success (137-139). Although beneficial actions have been reported with several different types of cell therapy, in many cases, protection of the infarcted myocardium was attributed to paracrine effects and to the modulation of inflammatory and fibrogenic signals rather than to activation of a regenerative program.

Several lines of evidence suggest that modulation of the ECM may be a crucial component of a regenerative response. First, in vitro, the composition of the ECM has a profound effect in regulation of cell cycle entry in cardiomyocyte progenitors and in neonatal cardiac myocytes $(140,141)$. Compliant matrices containing elastin promote dedifferentiation, proliferation, and clonal expansion of rat and mouse neonatal cardiomyocytes (140). Second, in fish and amphibians, myocardial regenerative responses seem to be dependent on deposition of a specialized ECM (142). A recent study reported that intramyocardial administration of ECM from healing zebrafish hearts may stimulate regeneration in mouse infarcts (143). Loss-of-function approaches suggested that fibronectin deposition may be critical for regeneration of the zebrafish heart (144). In newts, cardiac regeneration following injury was preceded by formation of a matrix network comprising tenascin- $\mathrm{C}$, fibronectin, and hyaluronan. This specialized matrix network may serve as a path for progenitor cells as well as play an active role in activation of a regenerative program (145). Considering that, much like in fish and amphibians, myocardial infarction in mammals also induces a marked upregulation of tenascin- $\mathrm{C}$ and fibronectin without stimulating remuscularization, it is unlikely that matrix-dependent actions are sufficient to activate a regenerative program. Myocardial regeneration likely requires not only a "regenerative" matrix profile, but also local secretion of a yet-undefined combination of cytokines and growth factors, and activation of pathways that enhance plasticity of progenitor cell populations (146). Third, in several cell therapy studies in mammalian models of cardiac injury, application of matrix-based patches containing progenitor cells showed enhanced effectiveness $(147,148)$. It has been suggested that application of matrix patches that recapitulate the regenerative environment of the embryonic myocardium may increase 
remuscularization following injury (149). Whether such effects may be due to direct actions of specific matrix proteins on cardiac progenitors or reflect matrix-dependent activation of other cell types (such as immune or vascular cells) remains unknown. Fourth, some experimental studies in mammals have suggested that matricellular macromolecules may induce proliferation of differentiated cardiomyocytes. Kühn and coworkers showed that recombinant periostin administered as an epicardial Gelfoam patch following infarction improved cardiac function and attenuated cardiac remodeling, triggering cell cycle reentry in differentiated cardiomyocytes in an integrin-dependent manner (150). Unfortunately, genetic manipulation of periostin expression in mice did not support the proposed proliferative actions of periostin on cardiomyocytes (151). Whether modulation of the matricellular protein profile following myocardial injury could facilitate activation of a regenerative program in adult infarcted hearts remains unknown.

A growing body of experimental work attempts to exploit technological advances in perfusion-decellularization strategies (152) to generate scaffolds comprising human cardiac ECM that may serve as tools for manufacture of cardiac grafts (153, 154). The acellular matrix obtained through decellularization could subsequently be used for recellularization with cardiomyocytes derived from induced pluripotent stem cells (iPSCs) in order to generate myocardial-like structures. Early studies have generated tissue constructs with definitive sarcomeric structure that exhibit contractile function and electrical conduction (153). Clearly, the current technology has significant limitations, and major advances are needed in order to pursue clinical translation. Complete reendothelialization is necessary to prevent activation of the coagulation system, generation of functional valvular structures is critical for ventricular function, and a conduction system is needed for transmission of electrical activity. Despite these problems, such matrix-driven strategies may represent the first step toward the generation of functional human cardiac grafts.

\section{Conclusions}

All myocardial cells are enmeshed within a dynamic network of ECM that not only serves a structural role and facilitates mechanical force transmission, but also regulates cell phenotype and function. Following cardiac injury, changes in composition of the cardiac ECM critically regulate inflammatory, reparative, fibrotic, and regenerative responses. Over the last two decades, understanding of the biology of the cardiac matrix has expanded well beyond the early concepts focusing on the role of matrix proteins in cardiac mechanics. We now view the matrix as a dynamic entity that responds to injury by undergoing dramatic transformations. Release of bioactive fragments and incorporation of matricellular proteins expands the functional repertoire of the matrix and drives repair by transducing key signals to many different cell types. Expansion of our knowledge on the structure, proteomic profile, and functional properties of matrix constituents will enrich our understanding of the pathobiology of heart disease, suggesting new therapeutic opportunities.

\section{Acknowledgments}

NGF's laboratory is supported by NIH grants R01 HL76246 and R01 HL85440 and by grants PR151134 and PR151029 from the Department of Defense Congressionally Directed Medical Research Programs (CDMRP).

Address correspondence to: Nikolaos G. Frangogiannis, The Wilf Family Cardiovascular Research Institute, Albert Einstein College of Medicine, 1300 Morris Park Avenue, Forchheimer G46B, Bronx, New York 10461, USA. Phone: 718.430.3546; E-mail: nikolaos. frangogiannis@einstein.yu.edu.
1. Pinto AR, et al. Revisiting cardiac cellular composition. Circ Res. 2016;118(3):400-409.

2. Kong P, Christia P, Frangogiannis NG. The pathogenesis of cardiac fibrosis. Cell Mol Life Sci. 2014;71(4):549-574.

3. Berk BC, Fujiwara K, Lehoux S. ECM remodeling in hypertensive heart disease. J Clin Invest. 2007;117(3):568-575.

4. Prabhu SD, Frangogiannis NG. The biological basis for cardiac repair after myocardial infarction: from inflammation to fibrosis. Circ Res. 2016;119(1):91-112.

5. Medugorac I, Jacob R. Characterisation of left ventricular collagen in the rat. Cardiovasc Res. 1983;17(1):15-21.

6. Leonard BL, Smaill BH, LeGrice IJ. Structural remodeling and mechanical function in heart failure. Microsc Microanal. 2012;18(1):50-67.

7. Bashey RI, Martinez-Hernandez A, Jimenez $\mathrm{SA}$. Isolation, characterization, and localization of cardiac collagen type VI. Associations with other extracellular matrix components. Circ Res. 1992;70(5):1006-1017.

8. Jugdutt BI. Ventricular remodeling after infarction and the extracellular collagen matrix: when is enough enough? Circulation.
2003;108(11):1395-1403.

9. Weber KT. Cardiac interstitium in health and disease: the fibrillar collagen network. J Am Coll Cardiol. 1989;13(7):1637-1652.

10. Frangogiannis NG. Pathophysiology of myocardial infarction. Compr Physiol. 2015;5(4):1841-1875.

11. Dobaczewski M, Gonzalez-Quesada C, Frangogiannis NG. The extracellular matrix as a modulator of the inflammatory and reparative response following myocardial infarction. J Mol Cell Cardiol. 2010;48(3):504-511.

12. Frangogiannis NG. Matricellular proteins in cardiac adaptation and disease. Physiol Rev. 2012;92(2):635-688.

13. Murphy-Ullrich JE, Sage EH. Revisiting the matricellular concept. Matrix Biol. 2014;37:1-14.

14. Cannon RO, et al. Early degradation of collagen after acute myocardial infarction in the rat. $\mathrm{AmJ}$ Cardiol. 1983;52(3):390-395.

15. Whittaker P, Boughner DR, Kloner RA. Role of collagen in acute myocardial infarct expansion. Circulation. 1991;84(5):2123-2134.

16. Etoh T, et al. Myocardial and interstitial matrix metalloproteinase activity after acute myocardial infarction in pigs. Am J Physiol Heart Circ Physiol. 2001;281(3):H987-H994.
17. Wang W, Sawicki G, Schulz R. Peroxynitriteinduced myocardial injury is mediated through matrix metalloproteinase-2. Cardiovasc Res. 2002;53(1):165-174.

18. Alfonso-Jaume MA, et al. Cardiac ischemiareperfusion injury induces matrix metalloproteinase-2 expression through the AP-1 components FosB and JunB. Am JPhysiol Heart Circ Physiol. 2006;291(4):H1838-H1846.

19. Danielsen CC, Wiggers H, Andersen HR. Increased amounts of collagenase and gelatinase in porcine myocardium following ischemia and reperfusion. JMol Cell Cardiol. 1998;30(7):1431-1442.

20. Gearing AJ, et al. Matrix metalloproteinases and processing of pro-TNF- $\alpha$. J Leukoc Biol. 1995;57(5):774-777.

21. Van Lint P, Libert C. Chemokine and cytokine processing by matrix metalloproteinases and its effect on leukocyte migration and inflammation. JLeukoc Biol. 2007;82(6):1375-1381.

22. Feng G, Hao D, Chai J. Processing of CXCL12 impedes the recruitment of endothelial progenitor cells in diabetic wound healing. FEBS J. 2014;281(22):5054-5062.

23. Peng H, Wu Y, Duan Z, Ciborowski P, Zheng JC. Proteolytic processing of SDF- $1 \alpha$ by matrix 
metalloproteinase-2 impairs CXCR4 signaling and reduces neural progenitor cell migration. Protein Cell. 2012;3(11):875-882.

24. Denney H, Clench MR, Woodroofe MN. Cleavage of chemokines CCL2 and CXCL10 by matrix metalloproteinases-2 and -9: implications for chemotaxis. Biochem Biophys Res Commun . 2009;382(2):341-347.

25. Cox JH, Dean RA, Roberts CR, Overall CM. Matrix metalloproteinase processing of CXCL11/I-TAC results in loss of chemoattractant activity and altered glycosaminoglycan binding. J Biol Chem . 2008;283(28):19389-19399.

26. Cauwe B, Opdenakker G. Intracellular substrate cleavage: a novel dimension in the biochemistry, biology and pathology of matrix metalloproteinases. Crit Rev Biochem Mol Biol. 2010;45(5):351-423.

27. Schulz R. Intracellular targets of matrix metalloproteinase- 2 in cardiac disease: rationale and therapeutic approaches. Annu Rev Pharmacol Toxicol. 2007;47:211-242.

28. Ali MA, Cho WJ, Hudson B, Kassiri Z, Granzier $\mathrm{H}$, Schulz R. Titin is a target of matrix metalloproteinase-2: implications in myocardial ischemia/reperfusion injury. Circulation. 2010;122(20):2039-2047.

29. Wells JM, Gaggar A, Blalock JE. MMP generated matrikines. Matrix Biol. 2015;44-46:122-129.

30. Gaggar A, Weathington N. Bioactive extracellular matrix fragments in lung health and disease. J Clin Invest. 2016;126(9):3176-3184.

31. Akthar S, et al. Matrikines are key regulators in modulating the amplitude of lung inflammation in acute pulmonary infection. Nat Commun. 2015;6:8423.

32. Adair-Kirk TL, Senior RM. Fragments of extracellular matrix as mediators of inflammation. Int $J$ Biochem Cell Biol. 2008;40(6-7):1101-1110.

33. Senior RM, Griffin GL, Mecham RP. Chemotactic activity of elastin-derived peptides. J Clin Invest. 1980;66(4):859-862.

34. Weathington NM, et al. A novel peptide CXCR ligand derived from extracellular matrix degradation during airway inflammation. Nat Med. 2006;12(3):317-323.

35. Gaggar A, et al. A novel proteolytic cascade generates an extracellular matrix-derived chemoattractant in chronic neutrophilic inflammation. J Immunol. 2008;180(8):5662-5669.

36. Mydel P, et al. Neutrophil elastase cleaves laminin332 (laminin-5) generating peptides that are chemotactic for neutrophils. J Biol Chem. 2008;283(15):9513-9522.

37. Villarreal F, Omens J, Dillmann W, Risteli J, Nguyen J, Covell J. Early degradation and serum appearance of type I collagen fragments after myocardial infarction. J Mol Cell Cardiol. 2004;36(4):597-601.

38. Lauten A, Gerhard-Garcia A, Suhr F, Fischer JH, Figulla HR, Bloch W. Impact of ischemia-reperfusion on extracellular matrix processing and structure of the basement membrane of the heart. PLoS One. 2014;9(3):e92833.

39. Dobaczewski M, Bujak M, Zymek P, Ren G, Entman ML, Frangogiannis NG. Extracellular matrix remodeling in canine and mouse myocardial infarcts. Cell Tissue Res. 2006;324(3):475-488.

40. Huebener P, et al. CD44 is critically involved in infarct healing by regulating the inflammatory and fibrotic response. J Immunol. 2008;180(4):2625-2633.

41. Trial J, et al. Fibronectin fragments modulate monocyte VLA- 5 expression and monocyte migration. J Clin Invest. 1999;104(4):419-430.

42. Taylor KR, Trowbridge JM, Rudisill JA, Termeer CC, Simon JC, Gallo RL. Hyaluronan fragments stimulate endothelial recognition of injury through TLR4. JBiol Chem. 2004;279(17):17079-17084.

43. Teder $\mathrm{P}$, et al. Resolution of lung inflammation by CD44. Science. 2002;296(5565):155-158.

44. Lindsey ML, et al. A novel collagen matricryptin reduces left ventricular dilation post-myocardial infarction by promoting scar formation and angiogenesis. JAm Coll Cardiol. 2015;66(12):1364-1374.

45. O'Reilly MS, et al. Endostatin: an endogenous inhibitor of angiogenesis and tumor growth. Cell. 1997;88(2):277-285.

46. Okada M, Oba Y, Yamawaki H. Endostatin stimulates proliferation and migration of adult rat cardiac fibroblasts through PI3K/Akt pathway. Eur JPharmacol. 2015;750:20-26.

47. Hamano Y, et al. Physiological levels of tumstatin, a fragment of collagen IV $\alpha 3$ chain, are generated by MMP- 9 proteolysis and suppress angiogenesis via $\alpha \mathrm{V} \beta 3$ integrin. Cancer Cell. 2003;3(6):589-601.

48. Andersson L, et al. Rip2 modifies VEGF-induced signalling and vascular permeability in myocardial ischaemia. Cardiovasc Res. 2015;107(4):478-486.

49. Brown LF, et al. Expression of vascular permeability factor (vascular endothelial growth factor) by epidermal keratinocytes during wound healing. JExp Med. 1992;176(5):1375-1379.

50. Clark RA. Overview and general considerations of wound repair. In: Clark RA, Henson PM, eds. The Molecular and Cellular Biology of Wound Repair. New York, New York, USA: Plenum Press; 1988:3-33.

51. Flick MJ, et al. Leukocyte engagement of fibrin (ogen) via the integrin receptor $\alpha \mathrm{M} \beta 2 / \mathrm{Mac}-1$ is critical for host inflammatory response in vivo. JClin Invest. 2004;113(11):1596-1606.

52. Corbett SA, Schwarzbauer JE. Fibronectin-fibrin cross-linking: a regulator of cell behavior. Trends Cardiovasc Med. 1998;8(8):357-362.

53. Smiley ST, King JA, Hancock WW. Fibrinogen stimulates macrophage chemokine secretion through toll-like receptor 4. JImmunol. 2001;167(5):2887-2894.

54. Petzelbauer P, et al. The fibrin-derived peptide Bbeta15- 42 protects the myocardium against ischemia-reperfusion injury. Nat Med. 2005;11(3):298-304.

55. Roesner JP, et al. The fibrin-derived peptide Bbeta15-42 is cardioprotective in a pig model of myocardial ischemia-reperfusion injury. Crit Care Med. 2007;35(7):1730-1735.

56. Atar D, et al. Effect of intravenous FXO6 as an adjunct to primary percutaneous coronary intervention for acute ST-segment elevation myocardial infarction results of the F.I.R.E. (Efficacy of FX06 in the Prevention of Myocardial Reperfusion Injury) trial. J Am Coll Cardiol. 2009;53(8):720-729.

57. Martino MM, Briquez PS, Ranga A, Lutolf MP, Hubbell JA. Heparin-binding domain of fibrin(ogen) binds growth factors and promotes tissue repair when incorporated within a synthetic matrix. Proc Natl Acad Sci U S A. 2013;110(12):4563-4568.

58. Rienks M, Papageorgiou AP, Frangogiannis NG, Heymans S. Myocardial extracellular matrix: an ever-changing and diverse entity. Circ Res. 2014;114(5):872-888

59. Schäfer BM, Maier K, Eickhoff U, Todd RF, Kramer MD. Plasminogen activation in healing human wounds. Am J Pathol. 1994;144(6):1269-1280.

60. Motley MP, et al. A CCR2 macrophage endocytic pathway mediates extravascular fibrin clearance in vivo. Blood. 2016;127(9):1085-1096.

61. Creemers E, et al. Disruption of the plasminogen gene in mice abolishes wound healing after myocardial infarction. Am J Pathol. 2000;156(6):1865-1873.

62. Brown LF, Dubin D, Lavigne L, Logan B, Dvorak HF, Van de Water L. Macrophages and fibroblasts express embryonic fibronectins during cutaneous wound healing. Am J Pathol. 1993;142(3):793-801.

63. Ulrich MM, et al. Increased expression of fibronectin isoforms after myocardial infarction in rats. J Mol Cell Cardiol. 1997;29(9):2533-2543.

64. Kanisicak O, et al. Genetic lineage tracing defines myofibroblast origin and function in the injured heart. Nat Commun. 2016;7:12260.

65. Serini G, et al. The fibronectin domain ED-A is crucial for myofibroblastic phenotype induction by transforming growth factor-beta1. J Cell Biol. 1998;142(3):873-881.

66. Arslan F, et al. Lack of fibronectin-EDA promotes survival and prevents adverse remodeling and heart function deterioration after myocardial infarction. Circ Res. 2011;108(5):582-592.

67. Webber J, Meran S, Steadman R, Phillips A. Hyaluronan orchestrates transforming growth factor- $\beta 1$-dependent maintenance of myofibroblast phenotype. J Biol Chem. 2009;284(14):9083-9092.

68. Hattori N, et al. Pericellular versican regulates the fibroblast-myofibroblast transition: a role for ADAMTS5 protease-mediated proteolysis. J Biol Chem. 2011;286(39):34298-34310.

69. Toeda $\mathrm{K}$, et al. Versican is induced in infiltrating monocytes in myocardial infarction. Mol Cell Biochem. 2005;280(1-2):47-56.

70. Bornstein P. Matricellular proteins: an overview. JCell Commun Signal. 2009;3(3-4):163-165.

71. Murphy-Ullrich JE. The de-adhesive activity of matricellular proteins: is intermediate cell adhesion an adaptive state? J Clin Invest. 2001;107(7):785-790.

72. Bornstein P, Sage EH. Matricellular proteins: extracellular modulators of cell function. Curr Opin Cell Biol. 2002;14(5):608-616.

73. Mackie EJ, et al. Expression of tenascin by vascular smooth muscle cells. Alterations in hypertensive rats and stimulation by angiotensin II. Am J Pathol.1992;141(2):377-388.

74. Hashimoto S, Suzuki T, Dong HY, Yamazaki N, Matsushima K. Serial analysis of gene expression in human monocytes and macrophages. Blood. 1999;94(3):837-844.

75. Frangogiannis NG, et al. The critical role of endogenous Thrombospondin (TSP)- 1 in preventing expansion of healing myocardial infarcts. 
Circulation. 2005;111(22):2935-2942.

76. Willems IE, Arends JW, Daemen MJ. Tenascin and fibronectin expression in healing human myocardial scars. J Pathol. 1996;179(3):321-325.

77. Murry CE, Giachelli CM, Schwartz SM, Vracko R. Macrophages express osteopontin during repair of myocardial necrosis. Am J Pathol. 1994;145(6):1450-1462

78. Dewald O, et al. Of mice and dogs: speciesspecific differences in the inflammatory response following myocardial infarction. Am J Pathol. 2004;164(2):665-677.

79. Trueblood NA, et al. Exaggerated left ventricular dilation and reduced collagen deposition after myocardial infarction in mice lacking osteopontin. Circ Res. 2001;88(10):1080-1087.

80. Schellings MW, et al. Absence of SPARC results in increased cardiac rupture and dysfunction after acute myocardial infarction. J Exp Med. 2009;206(1):113-123.

81. Shimazaki M, et al. Periostin is essential for cardiac healing after acute myocardial infarction. J Exp Med. 2008;205(2):295-303.

82. Oka T, et al. Genetic manipulation of periostin expression reveals a role in cardiac hypertrophy and ventricular remodeling. Circ Res. 2007;101(3):313-321.

83. Kzhyshkowska J, et al. Novel function of alternatively activated macrophages: stabilin-1mediated clearance of SPARC. J Immunol. 2006;176(10):5825-5832.

84. Aisagbonhi O, Rai M, Ryzhov S, Atria N, Feoktistov I, Hatzopoulos AK. Experimental myocardial infarction triggers canonical Wnt signaling and endothelial-to-mesenchymal transition. Dis Model Mech. 2011;4(4):469-483.

85. Ubil E, et al. Mesenchymal-endothelial transition contributes to cardiac neovascularization. Nature. 2014;514(7524):585-590.

86. Zeisberg EM, et al. Endothelial-to-mesenchymal transition contributes to cardiac fibrosis. Nat Med. 2007;13(8):952-961.

87. Saxena A, et al. IL-1 induces proinflammatory leukocyte infiltration and regulates fibroblast phenotype in the infarcted myocardium. JImmunol. 2013;191(9):4838-4848.

88. Ren G, Michael LH, Entman ML, Frangogiannis NG. Morphological characteristics of the microvasculature in healing myocardial infarcts. J Histochem Cytochem. 2002;50(1):71-79.

89. Zhao W, Lu L, Chen SS, Sun Y. Temporal and spatial characteristics of apoptosis in the infarcted rat heart. Biochem Biophys Res Commun. 2004;325(2):605-611.

90. Takemura G, et al. Role of apoptosis in the disappearance of infiltrated and proliferated interstitial cells after myocardial infarction. Circ Res. 1998;82(11):1130-1138

91. Tomasek JJ, Gabbiani G, Hinz B, Chaponnier C, Brown RA. Myofibroblasts and mechanoregulation of connective tissue remodelling. Nat Rev Mol Cell Biol. 2002;3(5):349-363.

92. Hinz B. Formation and function of the myofibroblast during tissue repair. J Invest Dermatol. 2007;127(3):526-537.

93. Bhattacharyya $\mathrm{S}$, et al. Tenascin- $\mathrm{C}$ drives persistence of organ fibrosis. Nat Commun. 2016;7:11703.
94. Zymek P, et al. The role of platelet-derived growth factor signaling in healing myocardial infarcts. J Am Coll Cardiol. 2006;48(11):2315-2323.

95. Davis GE, Norden PR, Bowers SL. Molecular control of capillary morphogenesis and maturation by recognition and remodeling of the extracellular matrix: functional roles of endothelial cells and pericytes in health and disease. Connect Tissue Res. 2015;56(5):392-402.

96. Rivera LB, Brekken RA. SPARC promotes pericyte recruitment via inhibition of endoglin-dependent TGF- $\beta 1$ activity. J Cell Biol. 2011;193(7):1305-1319.

97. Sager HB, et al. Proliferation and recruitment contribute to myocardial macrophage expansion in chronic heart failure. Circ Res. 2016;119(7):853-864

98. Chen B, Frangogiannis NG. Macrophages in the remodeling failing heart. Circ Res. 2016;119(7):776-778.

99. Xia Y, Lee K, Li N, Corbett D, Mendoza L, Frangogiannis NG. Characterization of the inflammatory and fibrotic response in a mouse model of cardiac pressure overload. Histochem Cell Biol. 2009;131(4):471-481.

100.Abrahams C, Janicki JS, Weber KT. Myocardial hypertrophy in Macaca fascicularis. Structural remodeling of the collagen matrix. Lab Invest. 1987;56(6):676-683.

101. Herum KM, et al. Syndecan-4 is a key determinant of collagen cross-linking and passive myocardial stiffness in the pressure-overloaded heart. Cardiovasc Res. 2015;106(2):217-226.

102.Schwartzkopff B, Mundhenke M, Strauer BE. Remodelling of intramyocardial arterioles and extracellular matrix in patients with arterial hypertension and impaired coronary reserve. Eur Heart J. 1995;16(suppl I):82-86.

103. Moore-Morris T, et al. Resident fibroblast lineag es mediate pressure overload-induced cardiac fibrosis. J Clin Invest. 2014;124(7):2921-2934.

104.Ali SR, et al. Developmental heterogeneity of cardiac fibroblasts does not predict pathological proliferation and activation. Circ Res. 2014;115(7):625-635.

105. Kuster GM, et al. Mineralocorticoid receptor inhibition ameliorates the transition to myocar dial failure and decreases oxidative stress and inflammation in mice with chronic pressure overload. Circulation. 2005;111(4):420-427.

106. Grimm D, et al. Regulation of extracellular matrix proteins in pressure-overload cardiac hypertrophy: effects of angiotensin converting enzyme inhibition. J Hypertens. 1998;16(9):1345-1355.

107. Nishida M, et al. P2Y6 receptor-Galpha12/13 signalling in cardiomyocytes triggers pressure overload-induced cardiac fibrosis. EMBO J. 2008;27(23):3104-3115

108.Yu Q, Horak K, Larson DF. Role of T lymphocytes in hypertension-induced cardiac extracellular matrix remodeling. Hypertension 2006;48(1):98-104

109. Laroumanie $\mathrm{F}$, et al. CD $4^{+} \mathrm{T}$ cells promote the transition from hypertrophy to heart failure during chronic pressure overload. Circulation. 2014;129(21):2111-2124

110. Samuel JL, et al. Accumulation of fetal fibronectin mRNAs during the development of rat cardiac hypertrophy induced by pressure overload. J Clin Invest. 1991;88(5):1737-1746.

111. Xia Y, et al. Endogenous thrombospondin 1 protects the pressure-overloaded myocardium by modulating fibroblast phenotype and matrix metabolism. Hypertension. 2011;58(5):902-911.

112. Konstandin MH, et al. Fibronectin contributes to pathological cardiac hypertrophy but not physiological growth. Basic Res Cardiol. 2013;108(5):375.

113. Ulasova E, et al. Loss of interstitial collagen causes structural and functional alterations of cardiomyocyte subsarcolemmal mitochondria in acute volume overload. JMol Cell Cardiol. 2011;50(1):147-156.

114. Chen YW, et al. Dynamic molecular and histopathological changes in the extracellular matrix and inflammation in the transition to heart failure in isolated volume overload. Am J Physiol Heart Circ Physiol. 2011;300(6):H2251-H2260.

115. Hutchinson KR, Stewart JA Jr,Lucchesi PA. Extracellular matrix remodeling during the progression of volume overload-induced heart failure. JMol Cell Cardiol. 2010;48(3):564-569.

116. Fu L, Wei CC, Powell PC, Bradley WE, Collawn JF, Dell'Italia LJ. Volume overload induces autophagic degradation of procollagen in cardiac fibroblasts. J Mol Cell Cardiol. 2015;89(Pt B):241-250.

117. Chancey AL, Brower GL, Peterson JT, Janicki JS. Effects of matrix metalloproteinase inhibition on ventricular remodeling due to volume overload. Circulation. 2002;105(16):1983-1988.

118. Ryan TD, et al. Left ventricular eccentric remodeling and matrix loss are mediated by bradykinin and precede cardiomyocyte elongation in rats with volume overload. J Am Coll Cardiol. 2007;49(7):811-821.

119. Borer JS, et al. Myocardial fibrosis in chronic aortic regurgitation: molecular and cellular responses to volume overload. Circulation. 2002;105(15):1837-1842.

120. Russo I, Frangogiannis NG. Diabetes-associated cardiac fibrosis: Cellular effectors, molecular mechanisms and therapeutic opportunities. JMol Cell Cardiol. 2016;90:84-93.

121. Regan TJ, et al. Evidence for cardiomyopathy in familial diabetes mellitus. JClin Invest. 1977;60(4):884-899.

122. Hutchinson KR, Lord CK, West TA, Stewart JA. Cardiac fibroblast-dependent extracellular matrix accumulation is associated with diastolic stiffness in type 2 diabetes. PLoS One. 2013;8(8):e72080.

123. Gonzalez-Quesada C, et al. Thrombospondin-1 induction in the diabetic myocardium stabilizes the cardiac matrix in addition to promoting vascular rarefaction through angiopoietin-2 upregulation. Circ Res. 2013;113(12):1331-1344

124. Fischer VW, Barner HB, Larose LS. Pathomorphologic aspects of muscular tissue in diabetes mellitus. Hum Pathol.1984;15(12):1127-1136.

125. van Hoeven KH, Factor SM. A comparison of the pathological spectrum of hypertensive, diabetic, and hypertensive-diabetic heart disease. Circulation. 1990;82(3):848-855.

126. Raman P, Krukovets I, Marinic TE, Bornstein P, Stenina OI. Glycosylation mediates up-regulation of a potent antiangiogenic and proathero- 
genic protein, thrombospondin-1, by glucose in vascular smooth muscle cells. J Biol Chem. 2007;282(8):5704-5714.

127. Clarke SA, Richardson WJ, Holmes JW. Modifying the mechanics of healing infarcts: Is better the enemy of good? J Mol Cell Cardiol. 2016;93:115-124.

128. Silvestre JS, et al. Activation of cardiac aldosterone production in rat myocardial infarction: effect of angiotensin II receptor blockade and role in cardiac fibrosis. Circulation. 1999;99(20):2694-2701.

129. Honda S, et al. Trends in the clinical and pathological characteristics of cardiac rupture in patients with acute myocardial infarction over 35 years. J Am Heart Assoc. 2014;3(5):e000984.

130. Hayashidani S, et al. Targeted deletion of MMP-2 attenuates early LV rupture and late remodeling after experimental myocardial infarction. Am J Physiol Heart Circ Physiol. 2003;285(3):H1229-H1235

131. Holubec T, Caliskan E, Bettex D, Maisano F. Repair of post-infarction left ventricular free wall rupture using an extracellular matrix patch. Eur Cardiothorac Surg. 2015;48(5):800-803.

132. Hudson MP, et al. Effects of selective matrix metalloproteinase inhibitor (PG-116800) to prevent ventricular remodeling after myocardial infarction: results of the PREMIER (Prevention of Myocardial Infarction Early Remodeling) trial. J Am Coll Cardiol. 2006;48(1):15-20.

133. Cerisano G, et al. Early short-term doxycycline therapy in patients with acute myocardial infarction and left ventricular dysfunction to prevent the ominous progression to adverse remodelling: the TIPTOP trial. Eur Heart J. 2014;35(3):184-191.

134. Frangogiannis NG. The inflammatory response in myocardial injury, repair, and remodelling. Nat Rev Cardiol. 2014;11(5):255-265.

135. Sawyer AJ, Kyriakides TR. Matricellular proteins in drug delivery: Therapeutic targets, active agents, and therapeutic localization. Adv Drug Deliv Rev. 2016;97:56-68.

136. Bergman O, et al. Evidence for cardiomyocyte renewal in humans. Science. 2009;324(5923):98-102.

137. Laflamme MA, Murray CE. Heart regeneration. Nature. 2011;473(7347):326-335.

138. Matsa E, Sallum K, Wu JC. Cardiac stem cell biology: glimpse of the past, present, and future. Circ Res. 2014;114(1):21-27.

139. Karantalis V, Hare JM. Use of mesenchymal stem cells for therapy of cardiac disease. Circ Res. 2015;116(8):1413-1430.

140. Yahalom-Ronen Y, Rajchman D, Sarig R, Geiger $\mathrm{B}$, Tzahor $\mathrm{E}$. Reduced matrix rigidity promotes neonatal cardiomyocyte dedifferentiation, proliferation and clonal expansion. Elife. 2015;4:e07455.

141. Qiu Y, et al. A role for matrix stiffness in the regulation of cardiac side population cell function. Am J Physiol Heart Circ Physiol. 2015;308(9):H990-H997.

142. Chablais F, Veit J, Rainer G, Jaźwińska A. The zebrafish heart regenerates after cryoinjuryinduced myocardial infarction. BMC Dev Biol. 2011;11:21.
143. Chen WC, et al. Decellularized zebrafish cardiac extracellular matrix induces mammalian heart regeneration. Sci Adv. 2016;2(11):e1600844.

144.Wang J, Karra R, Dickson AL, Poss KD. Fibronectin is deposited by injury-activated epicardial cells and is necessary for zebrafish heart regeneration. Dev Biol. 2013;382(2):427-435.

145. Mercer SE, Odelberg SJ, Simon HG. A dynamic spatiotemporal extracellular matrix facilitates epicardial-mediated vertebrate heart regeneration. Dev Biol. 2013;382(2):457-469.

146. Uygur A, Lee RT. Mechanisms of cardiac regeneration. Dev Cell. 2016;36(4):362-374.

147. Gaetani R, et al. Epicardial application of cardiac progenitor cells in a 3D-printed gelatin/hyaluronic acid patch preserves cardiac function after myocardial infarction. Biomaterials. 2015;61:339-348.

148.Jang J, et al. 3D printed complex tissue construct using stem cell-laden decellularized extracellular matrix bioinks for cardiac repair. Biomaterials. 2017;112:264-274.

149. Serpooshan V, et al. Use of bio-mimetic threedimensional technology in therapeutics for heart disease. Bioengineered. 2014;5(3):193-197.

150. Kühn B, et al. Periostin induces proliferation of differentiated cardiomyocytes and promotes cardiac repair. Nat Med. 2007;13(8):962-969.

151. Lorts A, Schwanekamp JA, Elrod JW, Sargent MA Molkentin JD. Genetic manipulation of periostin expression in the heart does not affect myocyte content, cell cycle activity, or cardiac repair. Circ Res. 2009;104(1):e1-7.

152. Ott HC, et al. Perfusion-decellularized matrix: using nature's platform to engineer a bioartificial heart. Nat Med. 2008;14(2):213-221.

153. Guyette JP, et al. Bioengineering human myocardium on native extracellular matrix. Circ Res. 2016;118(1):56-72.

154.Sánchez PL, et al. Acellular human heart matrix: A critical step toward whole heart grafts. Biomaterials. 2015;61:279-289.

155. Frangogiannis NG, Mendoza LH, Lewallen M, Michael LH, Smith SW, Entman ML. Induction and suppression of interferon-inducible protein-10 (IP-10) following experimental canine myocardial infarction may regulate angiogenesis. FASEB J. 2001;15(8):1428-30.

156. Chablais F, Jazwinska A. The regenerative capacity of the zebrafish heart is dependent on TGF $\beta$ signaling. Development. 2012;139(11):1921-1930.

157. Tamaoki $\mathrm{M}$, et al. Tenascin- $\mathrm{C}$ regulates recruitment of myofibroblasts during tissue repair after myocardial injury. Am J Pathol. 2005;167(1):71-80.

158. McCurdy SM, et al. SPARC mediates early extracellular matrix remodeling following myocardial infarction. Am J Physiol Heart Circ Physiol. 2011;301(2):H497-H505.

159. Ahmed MS, et al. Mechanisms of novel cardioprotective functions of CCN2/CTGF in myocardial ischemia-reperfusion injury. Am J Physiol Heart Circ Physiol. 2011;300(4):H1291-H1302.

160. Gravning J, et al. Myocardial connective tissue growth factor (CCN2/CTGF) attenuates left ventricular remodeling after myocardial infarction. PLoS One. 2012;7(12):e52120.

161. Van Aelst LN, et al. Osteoglycin prevents cardiac dilatation and dysfunction after myocardial infarction through infarct collagen strengthening. Circ Res. 2015;116(3):425-436.

162.Zhou Y, Poczatek MH, Berecek KH, MurphyUllrich JE. Thrombospondin 1 mediates angiotensin II induction of TGF- $\beta$ activation by cardiac and renal cells under both high and low glucose conditions. Biochem Biophys Res Commun. 2006;339(2):633-641.

163. Muñoz-Pacheco P, et al. Eplerenone enhances cardioprotective effects of standard heart failure therapy through matricellular proteins in hypertensive heart failure. J Hypertens. 2013;31(11):2309-2319.

164. Belmadani S, et al. A thrombospondin-1 antagonist of transforming growth factor- $\beta$ activation blocks cardiomyopathy in rats with diabetes and elevated angiotensin II. Am J Pathol. 2007;171(3):777-789.

165. Schroen B, et al. Thrombospondin-2 is essential for myocardial matrix integrity: increased expression identifies failure-prone cardiac hypertrophy. Circ Res. 2004;95(5):515-522.

166. Swinnen M, et al. Absence of thrombospondin-2 causes age-related dilated cardiomyopathy. Circulation. 2009;120(16):1585-1597.

167. Frolova EG, et al. Thrombospondin-4 regulates fibrosis and remodeling of the myocardium in response to pressure overload. FASEB J. 2012;26(6):2363-2373.

168. Mustonen E, et al. Thrombospondin-4 expression is rapidly upregulated by cardiac overload. Biochem Biophys Res Commun. 2008;373(2):186-191.

169.Lynch JM, et al. A thrombospondin-dependent pathway for a protective ER stress response. Cell. 2012;149(6):1257-1268.

170. Palao T, Rippe C, van Veen H, VanBavel E, Swärd K, Bakker EN. Thrombospondin-4 knockout in hypertension protects smallartery endothelial function but induces aortic aneurysms. Am J Physiol Heart Circ Physiol. 2016;310(11):H1486-H1493.

171. Cingolani $\mathrm{OH}$, et al. Thrombospondin- 4 is required for stretch-mediated contractility augmentation in cardiac muscle. Circ Res. 2011;109(12):1410-1414.

172. Yamamoto K, Dang QN, Kennedy SP, Osathanondh R, Kelly RA, Lee RT. Induction of tenascin- $\mathrm{C}$ in cardiac myocytes by mechanica deformation. Role of reactive oxygen species. J Biol Chem . 1999;274(31):21840-21846.

173. Hessel M, Steendijk P, den Adel B, Schutte C, van der Laarse A. Pressure overload-induced right ventricular failure is associated with re-expression of myocardial tenascin- $\mathrm{C}$ and elevated plasma tenascin-C levels. Cell Physiol Biochem. 2009;24 (3-4):201-210.

174. Shimojo N, et al. Tenascin-C may accelerate cardiac fibrosis by activating macrophages via the integrin $\alpha \mathrm{V} \beta 3$ /nuclear factor- $\mathrm{B}$ /interleukin-6 axis. Hypertension. 2015;66(4):757-766.

175. Bradshaw AD, et al. Pressure overload-induced alterations in fibrillar collagen content and myocardial diastolic function: role of secreted protein acidic and rich in cysteine (SPARC) in post-synthetic procollagen processing. Circulation. 2009;119(2):269-280.

176. Harris BS, Zhang Y, Card L, Rivera LB, Brek- 
ken RA, Bradshaw AD. SPARC regulates collagen interaction with cardiac fibroblast cell surfaces. Am J Physiol Heart Circ Physiol. 2011;301(3):H841-H847.

177. Matsui $Y$, et al. Role of osteopontin in cardiac fibrosis and remodeling in angiotensin IIinduced cardiac hypertrophy. Hypertension . 2004;43(6):1195-1201.

178. Xie Z, Singh M, Singh K. Osteopontin modulates myocardial hypertrophy in response to chronic pressure overload in mice. Hypertension.
2004;44(6):826-831.

179. Singh K, et al. Myocardial osteopontin expression coincides with the development of heart failure. Hypertension. 1999;33(2):663-670.

180. Collins AR, et al. Osteopontin modulates angiotensin II-induced fibrosis in the intact murine heart. J Am Coll Cardiol. 2004;43(9):1698-1705.

181. Lorenzen JM, et al. Osteopontin is indispensible for AP1-mediated angiotensin II-related miR-21 transcription during cardiac fibrosis. Eur Heart J . 2015;36(32):2184-2196.
182.López B, et al. Osteopontin-mediated myocardial fibrosis in heart failure: a role for lysyl oxidase? Cardiovasc Res. 2013;99(1):111-120.

183. Sam F, et al. Mice lacking osteopontin exhibit increased left ventricular dilation and reduced fibrosis after aldosterone infusion. Am J Hypertens. 2004;17(2):188-193.

184.Wang D, et al. Effects of pressure overload on extracellular matrix expression in the heart of the atrial natriuretic peptide-null mouse. Hypertension. 2003;42(1):88-95. 